\title{
GP2, the Homologue to the Renal Cast Protein Uromodulin, Is a Major Component of Intraductal Plugs in Chronic Pancreatitis
}

\author{
Steven D. Freedman, Kaori Sakamoto, and Rama P. Venu* \\ Division of Gastroenterology, Charles A. Dana Research Institute and Thorndike Laboratory, Beth Israel Hospital, Harvard Medical \\ School, Boston, Massachusetts 02215; and *Division of Gastroenterology, Medical College of Wisconsin, Milwaukee, Wisconsin 53403
}

\begin{abstract}
Protein plug obstruction of the pancreatic duct is one of the early events in chronic pancreatitis yet little is known about its pathogenesis. GP2, a protein in the exocrine pancreas, is a glycosyl phosphatidylinositol-anchored protein that is cleaved from the zymogen granule membrane and secreted into pancreatic juice. Since its homologue, uromodulin, is involved in renal cast formation, we asked the question whether GP2 might play a similar role in plug formation in chronic pancreatitis. The protein composition of intraductal plugs from patients with noncalcific chronic pancreatitis was examined. Plugs purified from pancreatic juice obtained by endoscopic cannulation were analyzed by SDS-PAGE. A 97-kD protein was found not only to be a reproducible constituent but also enriched within intraductal plugs. This protein was confirmed as GP2 by its localization to zymogen granule membranes, its isoelectric point, and by Western blotting. Although the pancreatic stone protein was identified in plugs, it was not a major reproducible component. These results demonstrate that GP2 is an integral component of plugs in pancreatic juice and suggest that GP2 may play a role in pancreatic plug formation that is analogous to the role played by uromodulin in the pathogenesis of renal casts. ( $J$. Clin. Invest. 1993. 92:83-90.) Key words: pancreatitis $•$ pancreatic duct $\bullet$ aggregation $\bullet$ proteases $\bullet$ protein precipitation
\end{abstract}

\section{Introduction}

The pancreatic acinar cell has served as an important paradigm for the study of cell function over the past few decades. Despite the progress made in understanding normal function, pathophysiological processes such as pancreatitis remain poorly understood. Studies of chronic pancreatitis have focused on the formation of calcifications within the pancreatic duct system. A decrease in the concentration of the pancreatic stone protein in pancreatic juice has been implicated in this process (1), although data from other laboratories do not support this hypothesis (2).

Although the mechanism of calcific stone formation is an important aspect of pancreatic duct obstruction in chronic pancreatitis, it is clear that the earliest events in this process involve the formation of protein precipitates in the intralobular and

Address reprint requests to Steven D. Freedman, M.D., Ph.D., Beth Israel Hospital, DA-501, 330 Brookline Avenue, Boston, MA 02215.

Received for publication 14 September 1992 and in revised form 26 January 1993.

J. Clin. Invest.

(C) The American Society for Clinical Investigation, Inc. 0021-9738/93/07/83/08 \$2.00

Volume 92, July 1993, 83-90 interlobular ducts (3). These eosinophilic "plugs" may eventually form the nidus for calcium deposition. Therefore an understanding of the mechanism of protein plug formation in chronic pancreatitis might have important therapeutic implications. Like calcified stones, protein plugs can produce pancreatic duct obstruction leading to recurrent inflammation of the gland $(4,5)$. In fact, endoscopic removal of these aggregates has been shown to improve abdominal pain associated with chronic pancreatitis as well as biochemical parameters $(4,5)$.

Attempts to study these protein precipitates have been limited. These plugs contain multiple proteins, many of which are the classic secretory proteins found in pancreatic juice (6). Glycoproteins and acidic mucopolysaccharides are also present in varying amounts $(7,8)$. Morphologic analysis has demonstrated that plugs are initially formed by clusters of degenerating epithelial cells in a fine reticular meshwork, which then enlarge through the accretion of amorphous material to assume laminar structures (8). Calcium deposits may subsequently appear on their surface leading to the formation of stones within the pancreatic duct system. To date, a comprehensive study of the proteins comprising these plugs has not been reported. Previous studies have shown that pancreatic stone protein is a component of plugs from patients with chronic calcific pancreatitis (6). However, in these experiments, proteins were selectively extracted from plugs and protease inhibitors were not used.

We have been interested in GP2, the most abundant protein of the zymogen granule membrane of the exocrine pancreas. GP2 is anchored to the lipid bilayer via a glycosyl phosphatidylinositol linkage and released by a calcium-activated, thiol-dependent enzyme into the content of the zymogen granule (9). Through the process of exocytosis, GP2 is discharged into the pancreatic duct. However, its high abundance in the pancreatic duct system relative to that found in zymogen granules has suggested that this protein may be secreted from more than one intracellular pool (10). After cloning and sequencing GP2, a search of the Genbank database revealed one homologous protein, uromodulin (Tamm-Horsfall protein $)(11,12)$. This protein displays unique aggregation properties and is the major component of hyaline casts found in urine (13). Since GP2 also shows self-association properties and can form aggregates (11), we have asked the question whether this molecule is involved in protein plug formation in pancreatic ducts from patients with chronic pancreatitis. An abstract of this work has been presented (14).

\section{Methods}

Materials. FOY-305 was obtained from Sanol Schwartz (Mannheim, Germany); ${ }^{125}$ I-labeled goat anti-rabbit IgG from ICN Biochemicals (Irvine, CA); monoclonal antibody to human pancreatic stone protein from Immunotech (Marseille, France); goat anti-human TammHorsfall protein (uromodulin) antisera from United States Biochemical Corp. (Cleveland, $\mathrm{OH}$ ); protein $\mathrm{G}$ gold, gold enhancement kit, 
protein G-alkaline phosphatase, ampholytes, and Coomassie brilliant blue R 250 from Bio-Rad Laboratories (Richmond, CA); aprotinin and PMSF from Sigma Chemical Co. (St. Louis, MO); and Immobilon-P transfer membranes from Millipore (Bedford, MA). Normal human pancreatic tissue (which would otherwise be discarded) from live donors was obtained from the International Institute for the Advancement of Medicine (Exton, PA) in accordance with the Beth Israel Hospital Committee on Clinical Investigations protocol no. 91-11-211905.

Preparation of human zymogen granules and membranes. The same fractionation procedure used for canine pancreas $(9)$ was adapted to prepare highly enriched fractions of human zymogen granules and zymogen granule membranes with the following modifications: tissue in Wisconsin's transplant solution was obtained on ice within $14 \mathrm{~h}$ of removal from the donor. Vessels, fat, and extraneous tissue were removed. Extensive mincing was required because of the presence of dense connective tissue. Zymogen granules were prepared from the $1,000 \mathrm{~g}$ pellet using self-forming Percoll gradients (9). Zymogen granule membranes were obtained by lysing the granules in $0.1 \mathrm{M}$ sodium bicarbonate containing FOY-305 $(0.1 \mathrm{mg} / \mathrm{ml})$, aprotinin $(20 \mathrm{kal}-$ likrein inhibitor $\mathrm{U} / \mathrm{ml})$, and PMSF $(0.1 \mathrm{mM})$ followed by centrifugation at $220,000 \mathrm{~g}$ for $1 \mathrm{~h}$. The pellet was resuspended into $10 \mathrm{mM}$ 3-( $N$-morpholino)propanesulfonic acid, $\mathrm{pH}$ 7.0. All steps were performed at $4^{\circ} \mathrm{C}$. Protein concentration was determined according to Bradford (15).

Preparation of human uromodulin. Uromodulin (Tamm-Horsfall protein ) was isolated from normal urine by two cycles of precipitation in the presence of $0.57 \mathrm{M} \mathrm{NaCl}$ and solubilized by dialysis against 10 $\mathrm{mM}$ Tris, $\mathrm{pH} 8.0$, as originally described by Tamm and Horsfall (16).

Effects of $\mathrm{pH}$ on protein precipitation. To examine the effects of $\mathrm{pH}$ on protein precipitation in pancreatic juice, $90-\mu 1$ samples of normal human pancreatic juice were aliquoted into microfuge tubes. $10 \mu \mathrm{l}$ of 1 M Mes, pH 5.5, pH 6.0, or pH 7.0, or $1 \mathrm{M}$ Tris, $\mathrm{pH} 8.5$ ( $100 \mathrm{mM}$ final concentration of buffers), was added, followed by incubation for 30 min on ice. Samples were centrifuged at $13,000 \mathrm{~g}$ for $15 \mathrm{~min}$ and the supernatant fractions were removed. Proteins that may have pelleted were washed in the same buffer conditions except no pancreatic juice was present. Centrifugation was repeated, the supernate was discarded, and any proteins pelleted were resuspended into $20 \mu \mathrm{l}$ of the appropriate buffer. $10 \mu \mathrm{l}$ of pellet and supernate fractions was then analyzed by SDS-PAGE on $10 \%$ polyacrylamide gels. Proteins were visualized by Coomassie blue staining.

Pancreatic juice analysis. Pure pancreatic juice was obtained from two groups of patients who underwent endoscopic retrograde cholangio-pancreatography for evaluation of abdominal pain. The first group, consisting of a total of 12 patients, had chronic pancreatitis as determined by an elevated amylase/lipase and/or the appropriate clinical features. These patients all had pancreatograms consistent with the diagnosis of chronic pancreatitis. The second group of patients $(n=2)$ had normal pancreatograms with no evidence of pancreatitis (normal pancreatic juice). Pure pancreatic juice was obtained by deep cannulation of the pancreatic duct without contrast administration. Pancreatic juice was aspirated before and after administration of parenteral secretin $(0.5 \mathrm{U} / \mathrm{kg})$. Samples were collected into tubes containing FOY -305 $(0.1 \mathrm{mg} / \mathrm{ml}$ final concentration $)$, immediately placed on ice, and then stored at $-20^{\circ} \mathrm{C}$. Generally $1-3 \mathrm{ml}$ of juice was collected. Pancreatic juice was also obtained from a patient with malignant obstruction of the pancreatic duct by cannulation of the duct during surgery. This patient was found to have an adenocarcinoma obstructing the duct at the head of the pancreas and underwent a successful pancreatico-duodenectomy. Juice was handled and processed under identical conditions as for the two groups described above. No patient complications occurred as a result of these procedures.

Protein plugs were isolated from pure pancreatic juice using the following protocol: after thawing, $1.0 \mathrm{ml}$ of pancreatic juice was centrifuged at $4^{\circ} \mathrm{C}$ for $15 \mathrm{~min}$ in a microfuge $(13,000 \mathrm{~g}$; Fisher Scientific Co., Pittsburgh, PA). The pellet was washed by resuspension in $0.5 \mathrm{ml}$ of buffer containing $250 \mathrm{mM} \mathrm{NaCl}, 10 \mathrm{mM}$ Tris, $\mathrm{pH} 8.0$, and $0.1 \mathrm{mg} / \mathrm{ml}$
FOY -305 at $4^{\circ} \mathrm{C}$ followed by recentrifugation. The pellet representing the washed protein plugs was resuspended into $50 \mu \mathrm{l}$ of $10 \mathrm{mM}$ Tris, pH 8.0 (containing $0.1 \mathrm{mg} / \mathrm{ml}$ FOY-305), by repeated homogenization with a pestle designed to fit the microfuge tube (Kontes, Vineland, $\mathrm{NJ}$ ).

Electrophoresis. SDS-PAGE was performed using $10 \%$ polyacrylamide gels as previously described (9). Although the plugs were diffcult to suspend, complete solubilization was achieved with sonication followed by the addition of (final concentrations) $1.6 \% \mathrm{SDS}, 0.11 \mathrm{M}$ Tris- $\mathrm{HCl}, \mathrm{pH} 7.5,6.6 \%$ sucrose, and $5 \%$ ( vol/vol) 2-mercaptoethanol and heating for $3 \mathrm{~min}$ at $90^{\circ} \mathrm{C} .10 \mu \mathrm{l}$ of each sample was analyzed on mini-gels using a Hoefer system (Hoefer Scientific Instruments, San Francisco, CA). Polypeptides were visualized with Coomassie brilliant blue R 250.

Two-dimensional gel electrophoresis was performed according to O'Farrell (17) with the following modifications: approximately $200 \mu \mathrm{g}$ of protein in $50 \mu$ l was subjected to isoelectric focusing (IEF) ${ }^{1}$ in the first dimension using a horizontal electrophoresis system (Multiphor; LKB Instruments Inc., Gaithersburg, MD). Proteins were separated using $5 \mathrm{~mA}$ constant current for $2 \mathrm{~h}$ followed by $500 \mathrm{~V}$ constant voltage for $12 \mathrm{~h}$. The lane containing the proteins was excised and subjected to SDS-PAGE ( $10 \%$ final acrylamide concentration) in the second dimension and then stained with Coomassie Brilliant Blue. pH determinations from the IEF gel were obtained by cutting out $1-\mathrm{cm}$ segments from the $12-\mathrm{cm}$-long gel, soaking those segments in $1.5 \mathrm{ml}$ of distilled water for $10 \mathrm{~min}$, with subsequent analysis with a pH electrode (Radiometer, Copenhagen, Denmark)

Western blotting was performed as previously described $(9,11)$. To analyze GP2 in human pancreatic juice and plugs, proteins were transferred for $5 \mathrm{~h}$ to Immobilon-P using a semidry electroblot apparatus (Multiphor; LKB Instruments Inc.) followed by incubation of the blot for $1 \mathrm{~h}$ with a 1:1,000 dilution of a rabbit polyclonal antibody to GP2 from canine zymogen granule membranes. After washing, a 1-h incubation was performed using a 1:2,000 dilution of [ $\left.{ }^{125} \mathrm{I}\right] \mathrm{IgG}$ (goat antirabbit antibody). The blots were then washed, dried, and placed on Kodak XAR-5 x-ray film for $1 \mathrm{~d}$ with intensifying screens. For quantitation purposes, the band corresponding to GP2 was excised from the blot and counts were measured in an Apex gamma counter (Micromedic Systems, Inc., Huntsville, AL). For Western blot analysis of the pancreatic stone protein, blots were incubated with a 1:500 dilution of a monoclonal antibody to pancreatic stone protein for $4 \mathrm{~h}$. After washing, the blot was incubated for $4 \mathrm{~h}$ with protein $\mathrm{G}$ coupled to gold and then enhanced with the Gold Enhancement Kit (Bio-Rad Laboratories).

\section{Results}

To examine the complete protein composition of intraductal plugs from patients with noncalcific chronic pancreatitis, pure pancreatic juice was obtained from patients undergoing endoscopic retrograde cholangio-pancreatography. Previous studies have shown that the protein precipitates found in pancreatic juice collected by endoscopic cannulation of the pancreatic duct are similar to intraductal plugs seen in histological sections from patients with chronic pancreatitis. This is based on morphological appearance as well as histochemical findings ( 8 , 18 ). Since it is difficult to obtain surgical specimens that contain intraductal plugs, endoscopic cannulation of the pancreatic duct has made it possible to obtain pancreatic plugs floating within the juice. To ensure that protein aggregates obtained in this manner were not artifactually produced, the following controls were performed: first, freeze thawing of normal pancreatic juice or juice from patients with chronic pancreatitis where plugs had been removed by prior sedimentation produced no

1. Abbreviation used in this paper: IEF, isoelectric focusing. 
aggregation of proteins either by visual inspection or by sedimentation at $13,000 \mathrm{~g}$ for $15 \mathrm{~min}$ at $4^{\circ} \mathrm{C}$. Additionally, no aggregation was seen if normal pancreatic juice was incubated at $37^{\circ} \mathrm{C}$ for $30 \mathrm{~min}$. However, prolonged incubations of juice from patients with chronic pancreatitis for $24 \mathrm{~h}$ at $4^{\circ} \mathrm{C}$ or $>2 \mathrm{~h}$ at $37^{\circ} \mathrm{C}$ occasionally resulted in the transformation of juice into a gel. Therefore, samples were frozen immediately after they were obtained. Second, $\mathrm{pH}$ of pancreatic juice may vary secondary to pancreatitis, as a result of secretin stimulation, or because of the fact that it is a bicarbonate-buffered system that is then exposed to ambient air. To determine if $\mathrm{pH}$ influences protein precipitation, normal pancreatic juice was buffered by the addition of $100 \mathrm{mM}$ Mes (final concentration ) $\mathrm{pH} 5.5, \mathrm{pH}$ 6.0 , $\mathrm{pH} 7.0$, or $100 \mathrm{mM}$ Tris, $\mathrm{pH} 8.5$, followed by sedimentation. No precipitation of proteins was produced as determined by sedimentation at $13,000 \mathrm{~g}$ for $15 \mathrm{~min}$ (Fig. 1). This demonstrates that changes in $\mathrm{pH}$ do not lead to precipitation of pancreatic juice proteins under these conditions. Also, no significant change in the $\mathrm{pH}$ of pancreatic juice was found after incubation for $2 \mathrm{~h}$ at $4^{\circ}$ or $37^{\circ} \mathrm{C}$. Lastly, since proteolytic activation may lead to protein precipitation (19), pancreatic juice was collected into tubes containing the protease inhibitor FOY-305. If protease inhibitors were omitted or samples were allowed to stand at room temperature, extensive proteolysis was observed as determined by SDS-PAGE (data not shown).

Protein aggregates were readily observed in pancreatic juice from 10 of the 12 patients studied with chronic pancreatitis. This is comparable to previously published data where $65 \%$ of patients with chronic pancreatitis had precipitates found in their pancreatic juice obtained by endoscopic cannulation (6). These 1-3-mm white, gelatinous precipitates (Fig. 2) were sedimented by centrifugation of pancreatic juice at $13,000 \mathrm{~g}$ for 15 min at $4^{\circ} \mathrm{C}$. Using normal pancreatic juice from two patients, no protein aggregates were seen nor were pellets obtained after centrifugation. For the analysis of proteins comprising intraductal plugs, pellet fractions representing plugs were washed in high salt medium to remove nonspecifically adsorbed secretory proteins. Otherwise, analysis of unwashed plugs by SDS-PAGE revealed a protein pattern similar to total juice. Although the

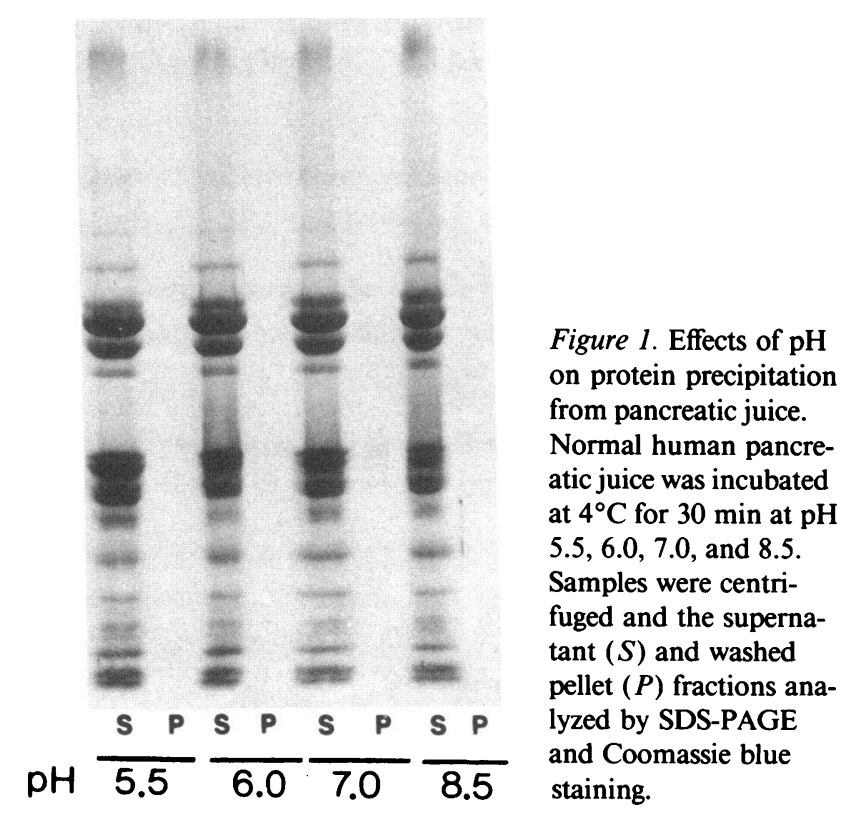

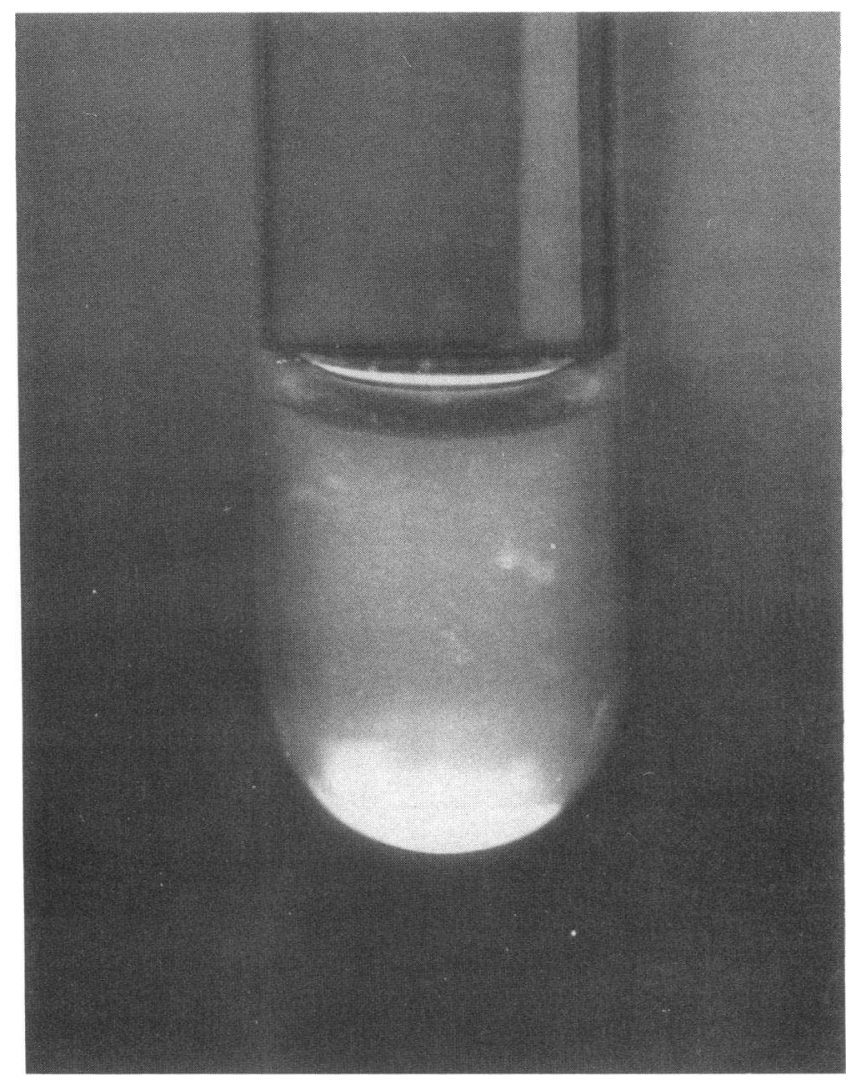

Figure 2. Typical appearance of protein plugs in pancreatic juice from a patient with idiopathic chronic pancreatitis. Numerous $1-3-\mathrm{mm}$ precipitates are seen.

plugs were difficult to suspend, complete solubilization was achieved by sonication followed by the addition of SDS, mercaptoethanol, and then heating to $90^{\circ} \mathrm{C}$. This methodology was found to provide the optimum approach to study all proteins that comprise intraductal plugs.

In Fig. 3, normal pancreatic juice obtained after secretin stimulation (lane $A$ ) is compared with juice from a patient with idiopathic chronic pancreatitis before (lane $B$ ), 5 min (lane $C$ ), and $20 \mathrm{~min}$ (lane $D$ ) after secretin administration. In lane $A$, the typical pattern of human secretory proteins is seen as described by Scheele (20). In lane $B$, a very different pattern is observed, which changes after secretin is given (lane $C$ ). If juice is collected for another $15 \mathrm{~min}$, the stoichiometry of these secreted proteins continues to change over time (lane $D$ ). Protein plugs were seen in pancreatic juice before secretin administration but were most evident in the secretin-stimulated samples, perhaps secondary to a "washing out" of concretions from the ducts. The washed protein plug sample from this patient with idiopathic pancreatitis is shown in lane $E$. Although some secretory proteins found in normal juice are seen, i.e., amylase, lipase, procarboxypeptidase, and serine proteases, there is enrichment of a protein with a relative molecular mass of 95100,000 (indicated by the arrow) in addition to several species $<20,000$. For comparison purposes, purified uromodulin $(85,000$ relative molecular mass) is shown in lane $F$.

To determine if certain polypeptides are reproducible constituents of intraductal plugs, total pancreatic juice and their respective plugs were analyzed from several patients with chronic pancreatitis that was secondary to alcohol (Fig. 4, pa- 


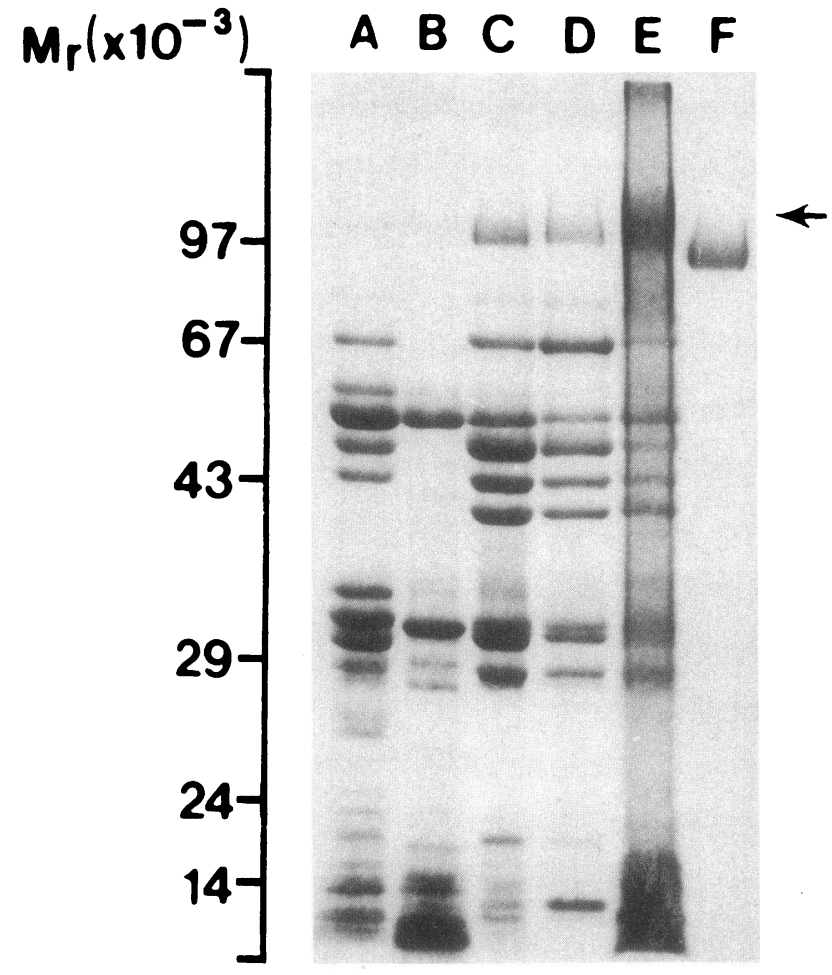

Figure 3. Comparison of normal pancreatic juice with juice from a patient with chronic idiopathic pancreatitis. Samples were analyzed by SDS-PAGE and proteins were visualized by Coomassie Blue. Molecular weights are designated on the vertical axis. Lane $A$, normal pancreatic juice. Lanes $B-D$ represent pancreatic juice from a patient with idiopathic chronic pancreatitis obtained before hormone administration (lane $B$ ), $5 \mathrm{~min}$ (lane $C$ ), and $20 \mathrm{~min}$ (lane $D$ ) after secretin administration. The washed protein plug samples from this patient with chronic pancreatitis is shown in lane $E$. The arrow depicts the position of the $95-100-\mathrm{kD}$ protein of interest. Purified human uromodulin is shown in lane $F$.

tients 1, 2, 3, and 4) or idiopathic in nature (patients 5 and 6). One patient with malignant obstruction of the duct with no clinical evidence of pancreatitis (patient 7) was also used. This latter patient was found to have an adenocarcinoma obstructing the head of the pancreas and underwent a pancreatico-duodenectomy at which time pancreatic juice containing protein precipitates was obtained by surgical cannulation of the duct. In Fig. 4, variability of the protein pattern is seen in the total juice samples $(J)$ with no distinguishing pattern between the different types of chronic pancreatitis at the level of one-dimensional SDS-PAGE. In contrast, a striking result is seen upon examination of the plugs $(P)$. One protein with a relative molecular mass of $\sim 97,000$ (indicated by the arrow) is reproducibly seen independent of the etiology of the pancreatitis. Relative to total pancreatic juice, this protein is not only present but enriched in these intraductal plugs. A 14-17-kD polypeptide is present in variable amounts. This is not present in some plugs (e.g., sample 3 ) but is quite dramatic in other samples, especially the patient with malignant obstruction of the duct. A few minor bands are seen, such as amylase ( $55 \mathrm{kD})$, but the fact they are diminished with washing of the plugs compared with total juice suggests these are nonspecifically adsorbed proteins and not intrinsic elements of the plugs.

Three lines of data demonstrate that the $97-\mathrm{kD}$ protein is human GP2. First, since GP2 is the major component of zymogen granule membranes from dog, rat, cow, pig, and rabbit exhibiting a molecular mass of 70-95 kD (21), this membrane fraction was prepared from human pancreas and examined for the presence of GP2. Normal human pancreas was procured through the International Institute for the Advancement of Medicine. The same fractionation procedure used for canine pancreas (9) was adapted to prepare fractions of human zymogen granules and zymogen granule membranes. A zymogen granule fraction was obtained using self-forming Percoll gradients with banding of the granules at the expected density in the gradient. A zymogen granule membrane fraction was generated by lysing the granules under alkaline conditions at $\mathrm{pH}$ 8.2 followed by sedimentation of the membranes. Analysis of these fractions by SDS-PAGE is shown in Fig. 5. The zymogen granule fraction shows the typical pattern of secretory proteins with the exception of prominent bands at $\sim 97$ and $40 \mathrm{kD}$, which are not seen in normal juice (Fig. 3, lane $A$ ). In contrast, in the zymogen granule membrane fraction, one polypeptide with an apparent relative molecular mass of 97-100,000 (indicated by the arrow) is the principal species comprising $>60 \%$ of the total protein. This is consistent with its identity being GP2. This polypeptide comigrates with the $97-\mathrm{kD}$ protein seen in intraductal plugs.

The second line of data for the identification of GP2 is based on two-dimensional gel electrophoresis of human protein plugs. In Fig. 6 is shown the one- and two-dimensional separation of a human protein plug sample from a patient with idiopathic chronic pancreatitis. Proteins were separated by IEF in the first dimension and our standard SDS-PAGE in the second dimension followed by Coomassie Blue staining. For comparative purposes on the same gel, the one-dimensional separation of the same sample by SDS-PAGE is shown. This demonstrates that the $97-\mathrm{kD}$ polypeptide (indicated by the arrow) has a pl of $\sim 4.8-5.2$ consistent with the known acidic pI for GP2 in other species.

The third line of data is Western blot analysis. For this purpose, our previously characterized polyclonal rabbit antibody to GP2 purified from canine zymogen granule membranes was used $(9,11)$. This antibody was chosen since polyclonal antibodies to GP2 from rat zymogen granule membranes or to human uromodulin showed no cross-reaction with human GP2 by Western blot. Fig. $7 A$ shows the Western blot analysis of the human zymogen granule membrane fraction with this antibody. One polypeptide with an apparent relative molecular mass of 97,000 is observed confirming its identity as GP2. No reaction was seen with preimmune sera (data not shown), validating the use of this antibody for the analysis of human GP2. Proteins from intraductal plugs of seven patients with idiopathic chronic pancreatitis (lanes 1-7) and precipitates from the patient with malignant obstruction of the duct (lane 8 ) were then analyzed by Western blot using this antibody. As shown at the top of Fig. $7 B$, the identity of the $97-\mathrm{kD}$ band is confirmed as GP2 and is present in all intraductal plug samples from the patients with chronic pancreatitis (lanes $1-7)$. Of note is the variation in the apparent mobility of GP2 on SDS-polyacrylamide gels. This molecule is known to migrate at different apparent molecular weights by SDS-PAGE, perhaps secondary to carbohydrate processing, proteolysis, or covalent modification (10). However, examination of Figs. 4 and 7 shows no particular pattern in the apparent molecular weights of GP2 with regard to the etiology of the chronic pan- 


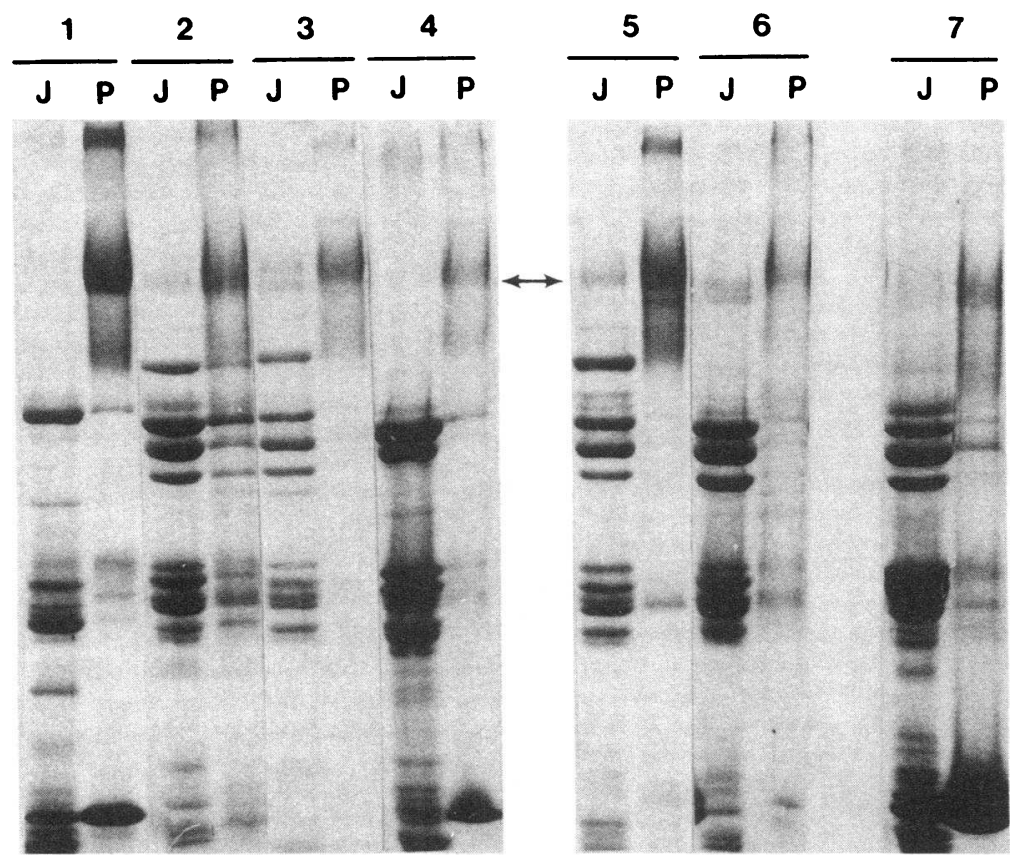

Figure 4. Comparison of the protein composition of human pancreatic juice and their respective plugs from seven patients (labeled 1-7) with chronic pancreatitis. Patients 1-4 had chronic alcoholic pancreatitis; patients 5 and 6 had chronic idiopathic pancreatitis; patient 7 was found to have malignant obstruction of the pancreatic duct with no clinical evidence of pancreatitis. Total juice $(J)$ obtained after secretin stimulation is shown next to plugs $(P)$ taken from the same patient. Samples were analyzed by SDS-PAGE and the proteins visualized with Coomassie Blue. The arrow indicates the position of the $97-100-\mathrm{kD}$ protein. creatitis or in comparison to the zymogen granule and zymogen granule membrane fractions from human pancreas.

Concomitantly, the same samples were analyzed by Western blot using a monoclonal antibody to the pancreatic stone protein and visualized using protein $G$ coupled to alkaline phosphatase. At the bottom of Fig. $7 \mathrm{~B}$, although the pancreatic stone protein is seen in most samples, it is marginally present in patients 6 and 7. As expected for this monoclonal antibody (22), multiple polypeptides with molecular weights between 14,000 and 17,000 are seen. Although it has been speculated that specific forms of the stone protein are associated with intraductal plugs, at least three different molecular weight forms of the pancreatic stone protein are observed in plugs from the seven patients with chronic pancreatitis that were analyzed.

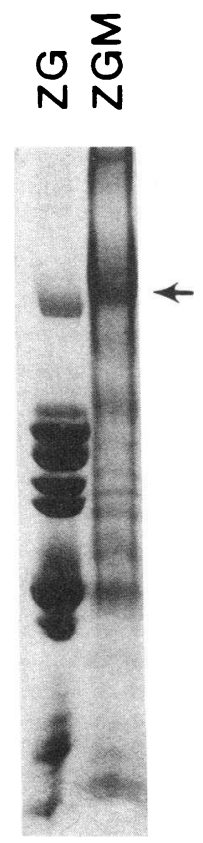

Figure 5. Analysis of human zymogen granule $(Z G)$ and zymogen granule membrane ( $Z G M)$ fractions. These fractions were prepared by subcellular fractionation and the proteins separated by SDS-PAGE. The Coomassie Blue-stained protein pattern is shown. The arrow indicates the position of the $97-\mathrm{kD}$ protein.
Pancreatic juice precipitates from the patient with pancreatic adenocarcinoma (see Fig. 4, sample $7 P$ ) were also analyzed by Western blot (Fig. 7B, lane 8). Low levels of GP2 are detected. In contrast, the pancreatic stone protein is the major component comigrating with the predominant band seen in Coomassie Blue-stained gels.

The quantitation of GP2 in total pancreatic juice compared with plugs from four patients with chronic pancreatitis is shown in Table I. Using equal amounts of protein per lane on the gel, followed by Western blotting with [ $\left.{ }^{125} \mathrm{I}\right] \mathrm{IgG}$ as the secondary antibody, the band corresponding to GP2 was excised and counts were measured. As shown in Table $I$, a 3.8-11.9fold increase in GP2 is found within plugs relative to total juice. These results demonstrate that GP2 is not only present but significantly enriched within intraductal plugs.

\section{Discussion}

The results of this study demonstrate that GP2, the homologue to the renal cast protein uromodulin, is a component of intraductal plugs from patients with noncalcific chronic pancreatitis. These results were observed independent of whether plugs were obtained from patients with either idiopathic or alcoholic pancreatitis. The fact that GP2 was enriched within these protein aggregates compared with that found in total pancreatic juice suggests that this protein may play an important role in the pathogenesis of intraductal plug formation rather than representing an epiphenomena or the nonspecific association of a secretory protein within these structures.

In one patient with pancreatic adenocarcinoma, pancreatitis was not clinically evident, yet protein precipitates were present within the patient's pancreatic juice. This indicates that pancreatitis may not be an absolute prerequisite for the formation of protein aggregates within the duct system. Pancreatic plugs have been found in juice from patients without pancreatic pathology, although this occurrence is relatively uncommon (6). Analysis of the intraductal precipitates from our single patient with malignancy demonstrated that the pancreatic 


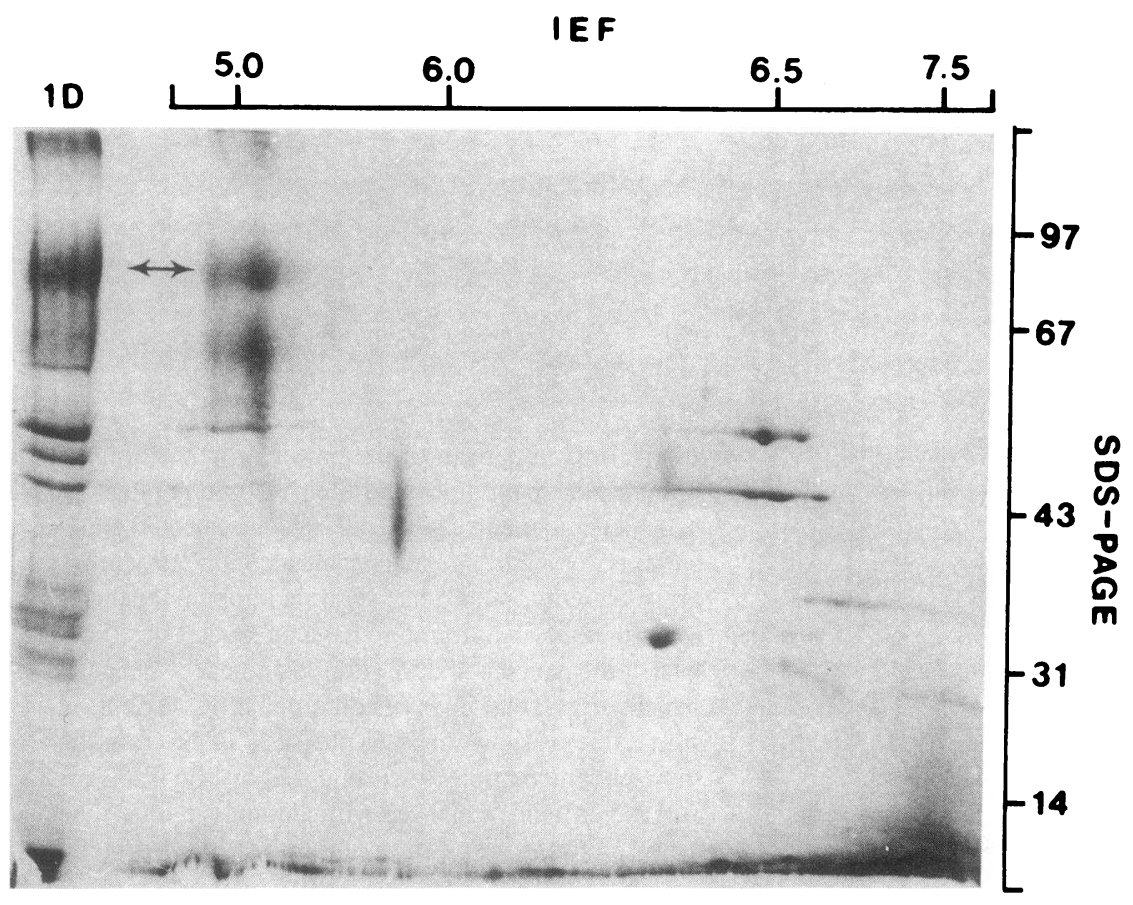

Figure 6. One- and two-dimensional gel analysis of protein plugs from a patient with idiopathic chronic pancreatitis. Proteins were separated in the first dimension by IEF and in the second dimension by SDS-PAGE followed by staining with Coomassie Blue. For comparative purposes on the same gel, the protein sample was also analyzed by one-dimensional SDSPAGE. The arrow indicates the position of the 97-kD protein. stone protein was the major component. In contrast, in patients with chronic pancreatitis, GP2 was the predominant reproducible protein component of plugs. This observation may imply that intraductal precipitates seen in obstructive disease in the absence of pancreatitis is a different process. Therefore, referring to all precipitates as "plugs" may be inaccurate. The predominance of the pancreatic stone protein in precipitates from malignant obstruction of the duct suggests that stasis of pancreatic juice from any cause might lead to the formation of insoluble complexes containing this protein. Two types of protein precipitates in surgically derived pancreatic juice have been described (19). The first type of protein precipitate consists of the formation of fine particles at $4{ }^{\circ} \mathrm{C}$ in very concentrated pancreatic juice $(40 \mathrm{mg} / \mathrm{ml})$ that dissolve upon warming to $37^{\circ} \mathrm{C}$. This was identified in proteolytically inactive samples and thought to represent concentration-dependent precipitation of proteins. In our current study, this phenomenon was not observed. The second type of protein precipitate was characterized by insoluble flocculent precipitates in proteolytically active pancreatic juice. No solubilization occurred at $37^{\circ} \mathrm{C}$ and precipitates were found independent of protein concentration. This latter type of protein aggregate is thought to be representative of the intraductal plugs associated with chronic pancreatitis. These findings are consistent with the structures identified as containing GP2 in our study. Furthermore, intraductal plugs observed in histological sections from patients with chronic pancreatitis are morphologically and histochemically similar to precipitates found in pancreatic juice collected by endoscopic cannulation of the pancreatic duct from these types of patients $(8,18)$. This implies that in the setting of chronic pancreatitis the aggregates we have described are intraductal plugs rather than nonspecific precipitates.

In patients with chronic pancreatitis, although GP2 was found to be an integral component of protein plugs in pancreatic juice, the pancreatic stone protein was also present, albeit in variable amounts. Diminished quantities of the stone protein have been postulated to lead to calcium precipitation and stone formation in chronic calcifying pancreatitis (1). However, Schmiegel et al. (2) have refuted this concept. Additionally, it is difficult to reconcile how the pancreatic stone protein, which is postulated to inhibit calcium precipitation, can be a component of plugs, which eventually calcify. In our study, the

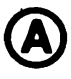

ZGM

GP2

(B)

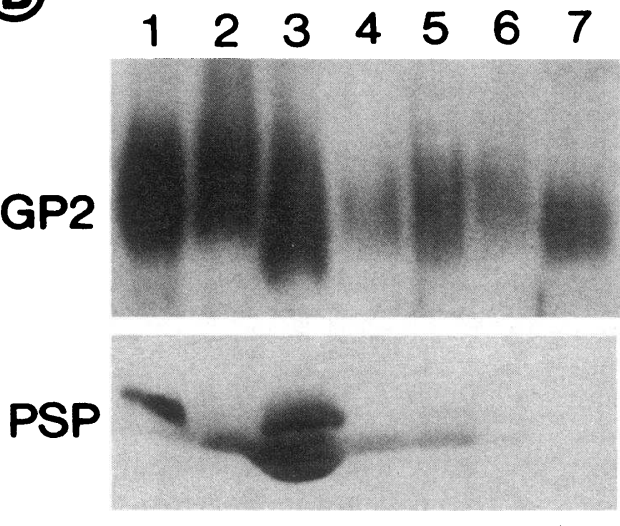

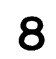

Figure 7. Western blot analysis of GP2 and the pancreatic stone protein. $(A)$ The human zymogen granule membrane fraction was subjected to SDS-PAGE followed by Western blot analysis using a polyclonal antibody to GP2. For visualization, the blot was then reacted with protein G-alkaline phosphatase. (B) Protein aggregates from seven patients with idiopathic chronic pancreatitis (lanes 1-7) and from the patient with malignant obstruction of the duct (lane 8 ) were separated by SDSPAGE and subjected to Western blot analysis using antibodies to either GP2 (top) or pancreatic stone protein (PSP) (bottom). 
Table I. Quantitation of GP2 in Plugs Compared with That Found in Total Pancreatic Juice from Four Patients with Idiopathic Chronic Pancreatitis

\begin{tabular}{ccc}
\hline CPM in plugs & CPM in juice & $\begin{array}{c}\text { Ratio of GP2 in plugs relative } \\
\text { to juice }\end{array}$ \\
\hline 593 & 158 & 3.8 \\
428 & 36 & 11.9 \\
521 & 48 & 10.9 \\
367 & 72 & 5.1 \\
\hline
\end{tabular}

pancreatic stone protein was not consistently found as a major component of protein plugs from patients with noncalcific chronic pancreatitis. The reason for this discrepancy may be in the methods used. An important difference from previously published reports examining protein plugs is the fact that we did not use selective solubilization of proteins from plugs using saline-, citrate-, or pH 9-buffered solutions. After extraction of plugs for $1 \mathrm{~h}$ under these conditions, multiple proteins were left in the insoluble fraction, including GP2 (unpublished observations). Thus, conditions were chosen whereby the complete protein composition of intraductal plugs could be analyzed in its entirety. Additionally, in our approach, pancreatic juice was collected directly into tubes containing the protease inhibitor FOY-305, which inhibits both trypsin and chymotrypsin. This was not used in previous studies. Since zymogens in human pancreatic juice are readily autoactivated, the use of protease inhibitors may be important in experiments designed to analyze all proteins comprising plugs. Trypsin can cleave the ArgIle residue near the $\mathrm{NH}_{2}$ terminus of the pancreatic stone protein, resulting in a $14-\mathrm{kD}$ polypeptide that appears to precipitate (23). Thus, omission of protease inhibitors may lead to artifactual localization of this protein in protein aggregates. One other important difference from previous studies is that our patients had noncalcific chronic pancreatitis. Whether the protein composition of plugs is different in the setting of intraductal calcifications remains to be determined.

Our study shows that GP2 and uromodulin not only share structural homology but functionally are similar in that both lead to ductal precipitates under pathological conditions. Although the exact mechanism of cast formation in the kidney is unknown, the fact that uromodulin can form large aggregates suggests that it plays a critical role in the genesis of precipitates within the renal tubules (13). This process is facilitated by increased concentrations of the mucoprotein, elevated electrolyte concentrations (e.g., from 0.1 to $0.3 \mathrm{M} \mathrm{NaCl}$ ), and a decrease in $\mathrm{pH}$ (24). Thus, ischemia and certain renal diseases may lead to the development of renal casts through one or more of the following mechanisms: $(a)$ increased concentration of proteins in the urine; $(b)$ alteration in ionic conditions; or $(c)$ excretion of novel or altered proteins into the renal tubules, which then form an insoluble complex with uromodulin. An analogous situation may be found in chronic pancreatitis. In this disease, protein secretion is increased without a compensatory rise in fluid and bicarbonate output (25). As a result, pancreatic juice protein concentration is increased and the $\mathrm{pH}$ is more acidic (26).

Since protein precipitates are not found diffusely throughout the pancreatic duct system but rather are sporadically distributed (3), it is unlikely that a global change in $\mathrm{pH}$, protein concentration, or ionic conditions is the principle factor in plug formation. In actuality, chronic pancreatitis appears to be a more focal process that involves multiple regions of the pancreas (3). Previous work by Allan and White (19) demonstrated that an increase in protein concentration in pancreatic juice is not enough to produce insoluble protein aggregates. Rather, the primary etiology behind plug formation may involve partial proteolytic activation, causing precipitation of proteins. Active trypsin and chymotrypsin have been found associated with protein precipitates in both acute (27) and chronic calcific pancreatitis (19). Whether protein obstruction leads to or is the result of premature activation of zymogens is still unknown.

Morphological and histochemical studies have suggested that pancreatic intraductal plugs arise by the interaction of desquamated epithelial cells with sulfated acidic mucopolysaccharides and glycoproteins $(8,18)$. Through condensation and accumulation of a fine reticular substance, aggregates, which subsequently enlarge, form. This reticular matrix does not appear to be the pancreatic stone protein (28). The following evidence suggests that GP2 comprises this fibrillar material: first, GP2 has been localized by immuno-gold labeling to thread-like fibrils in the acinar lumen of normal rat pancreas (10). Second, aggregates of fibrils that are present in the lumen of normal human pancreas are found in higher amounts in chronic pancreatitis in association with protein precipitates (29). Third, GP2, although present in a soluble form within zymogen granules, is secreted into normal pancreatic juice in a form that is now sedimentable at $200,000 \mathrm{~g}$ for $1 \mathrm{~h}(30)$. This is similar to uromodulin, which can polymerize into fibrils and other reticular structures depending on its physicochemical environment (31).

In conclusion, it appears that protein plug development in chronic pancreatitis shares some of the features seen in renal cast formation. Although the physiological function of GP2 and uromodulin is unknown, pathophysiologically they appear to play important roles in tubular/ductular obstruction in polarized epithelial cell systems. Since intraductal plug formation is one of the early inciting events in all types of chronic pancreatitis, including the idiopathic form, understanding the pathogenesis of these aggregates may lead to treatment of a disorder where few advances have taken place since its initial description.

\section{Acknowledgments}

The authors thank Dr. Michael Steer for providing pancreatic juice from the patient with malignant obstruction. We also thank Dr. Michael Steer and Dr. George Scheele for helpful discussions throughout this work.

$\mathrm{S}$. Freedman is a recipient of the American Gastroenterological Association/Hoffman-LaRoche Scholar Award.

\section{References}

1. Multigner, L., H. Sarles, D. Lombardo, and A. DeCaro. 1985. Pancreatic stone protein II. Implication in stone formation during the course of chronic calcifying pancreatitis. Gastroenterology. 89:387-391.

2. Schmiegel, W., M. Burchert, H. Kalthoff, C. Roeder, G. Butzow, H. Grimm, B. Kremer, N. Soehendra, H.-W. Schreiber, H.-G. Thiele, et al. 1990. Immunochemical characterization and quantitative distribution of pancreatic stone protein in sera and pancreatic secretions in pancreatic disorders. Gastroenterology. 99:1421-1430.

3. Nakamura, K., H. Sarles, and H. Payan. 1972. Three-dimensional reconstruction of the pancreatic ducts in chronic pancreatitis. Gastroenterology. 62:942-949. 
4. Harada, H., H. Miyake, H. Miki, T. Kibayashi, T. Sasaki, and I. Kimura. 1982. Role of endoscopic elimination of protein plugs in the treatment of chronic pancreatitis. Gastro. Jpn. 17:463-468.

5. Tsurumi, T., Y. Fujii, M. Takeda, J. Tanaka, H. Harada, and H. Oka. 1984. A case of chronic pancreatitis successfully treated by endoscopic removal of protein plugs. Acta Med. Okayama. 38:169-174.

6. Guy, O., G. Robles-Diaz, Z. Adrich, J. Sahel, and H. Sarles. 1983. Protein content of precipitates present in pancreatic juice of alcoholic subjects and patients with chronic calcifying pancreatitis. Gastroenterology. 84:102-107.

7. Harada, H., T. Hayashi, H. Miki, H. Miyake, K. Ochi, I. Kimura, M. Takeda, J. Tanaka, and T. Tanaka. 1983. Histochemical studies on enzyme-digested protein plugs of patients with chronic pancreatitis: a preliminary report. Acta Med. Okayama. 37:227-231.

8. Harada, H., O. Ueda, M. Yasuoka, T. Nakamura, K. Kunichika, I. Ikubo, F. Kochi, M. Shigetoshi, H. Yabe, E. Hanafusa, et al. 1981. Histochemical studies on protein plugs obtained by endoscopic retrograde catheterization of the papilla. Gastro. Jpn. 16:563-567.

9. Fukuoka, S.-I., S. Freedman, and G. Scheele. 1991. A single gene encodes membrane-bound and free forms of GP2, the major glycoprotein in pancreatic secretory (zymogen) granule membranes. Proc. Natl. Acad. Sci. USA. 88:28982902.

10. Havinga, J., J. Slot, and G. Strous. 1985. Membrane detachment and release of the major membrane glycoprotein of secretory granules in rat pancreatic exocrine cells. Eur. J. Cell Biol. 39:70-76.

11. Fukuoka, S.-I., S. Freedman, H. Yu, V. Sukhatme, and G. Scheele. 1992. GP2/THP gene family encodes self-binding glycosyl phosphatidyl inositol anchored proteins in apical secretory compartments of pancreas and kidney. Proc. Natl. Acad. Sci. USA. 89:1189-1193.

12. Hoops, T., and M. Rindler. 1991. Isolation of the cDNA encoding glycoprotein-2 (GP-2), the major zymogen granule membrane protein. J. Biol. Chem. 266:4257-4263. 396.

13. McQueen, E. 1962. The nature of urinary casts. J. Clin. Pathol. 19:392-

14. Freedman, S., R. Venu, and M. Steer. 1992. GP2, the homologue to the renal cast protein uromodulin, is a component of protein plugs in pancreatic juice. Gastroenterology. 102:266a. (Abstr.)

15. Bradford, M. 1976. A rapid and sensitive method for quantitation of microgram quantities of protein utilizing the principle of protein dye binding. Anal. Biochem. 72:248-254.

16. Tamm, I., and F. Horsfall. 1952. A mucoprotein derived from human urine which reacts with influenza, mumps and newcastle disease virus. $J$. Exp. Med. 95:71-87.
17. O'Farrell, P. 1975. High resolution two dimensional electrophoresis of proteins. J. Biol. Chem. 250:4007-4021.

18. Harada, H., O. Ueda, M. Yasuoka, T. Nakamura, T. Hayashi, T. Kobayashi, and I. Kimura. 1982. Scanning electron-microscopic studies on protein plugs obtained from patients with chronic pancreatitis. Gastro. Jpn. 17:98-101.

19. Allan, J., and T. White. 1974. An alternate mechanism for the formation of protein plugs in chronic calcifying pancreatitis. Digestion. 11:428-431.

20. Scheele, G. 1984. Analysis of human exocrine proteins in health and disease by use of two dimensional isoelectric focusing/sodium dodecyl sulfate gel electrophoresis. In Pancreatitis-Concepts and Classification. K. Gyk, M. Singer, and H. Sarles, editors. Elsevier, Amsterdam, The Netherlands. 88-95.

21. MacDonald, R., and R. Ronzio. 1972. Comparative analysis of zymogen granule membrane polypeptides. Biochem. Biophys. Res. Commun. 49:377-382.

22. Montalto, G., J. Bonicel, L., Multigner, M. Rovery, H. Sarles, and A. De Caro. 1986. Partial amino acid sequence of human pancreatic stone protein, a novel pancreatic secretory protein. Biochem. J. 238:227-232.

23. Rouimi, P., J. Bonicel, M. Rovery, and A. DeCaro. 1987. Cleavage of the Arg-Ile bond in the native polypeptide chain of human pancreatic stone protein. FEBS (Fed. Eur. Biochem. Soc.) Lett. 216:195-199.

24. McQueen, E., and G. Engel. 1966. Factors determining the aggregation of urinary mucoprotein. J. Clin. Pathol. (Lond.). 19:392-396.

25. Sahel, J., and H. Sarles. 1979. Modifications of pure human pancreatic juice induced by chronic alcohol consumption. Dig. Dis. Sci. 24:897-905.

26. Gerolami, A., C. Marteau, A. Matteo, J. Sahel, H. Portugal, A. Pauli, J. Pastor, and H. Sarles. 1989. Calcium carbonate saturation in human pancreatic juice: possible role of ductal $\mathrm{H}^{+}$secretion. Gastroenterology. 96:881-884.

27. Renner, I., H. Rinderknecht, and A. Douglas. 1978. Profiles of pure pancreatic secretions in patients with acute pancreatitis: the possible role of proteolytic enzymes in pathogenesis. Gastroenterology. 75:1090-1098.

28. Provensal-Cheylan, M., J. Bernard, A. Mariani, N. Soehendra, M. Cremer, J. Sahel, and H. Sarles. 1989. Occluded pancreatic endoprosthesesanalysis of the clogging material. Endoscopy. 21:63-69.

29. Kern, H., A. Warshaw, and G. Scheele. 1984. Fine structure of protein precipitations in acinar lumina of the normal human pancreas and in chronic pancreatitis. In Pancreatitis-Concepts and Classification. K. Gyk, M. Singer, and $\mathrm{H}$. Sarles, editors. Elsevier, Amsterdam, The Netherlands. 101-105.

30. Rindler, M., and T. Hoops. 1990. The pancreatic membrane protein GP-2 localizes specifically to secretory granules and is shed into the pancreatic juice as a protein aggregate. Eur. J. Cell Biol. 53:154-163.

31. Wiggins, R. 1987. Uromucoid (Tamm-Horsfall glycoprotein) forms different polymeric arrangements on a filter surface under different physicochemical conditions. Clin. Chim. Acta. 162:329-340. 